\title{
Myelin Vacuolation, Optic Neuropathy and Retinal Degeneration after Closantel Overdosage in Sheep and in a Goat
}

\author{
J.J. van der Lugt $^{\mathrm{a}}$ and I. Venter \\ *Companion Animal Studies, Faculty of Veterinary Science, University of Pretoria, \\ Private Bag X05, 0110 Onderstepoort, South Africa \\ ${ }^{\mathrm{a}}$ Departments of Paraclinical Sciences
}

\section{Summary}

Toxicity of closantel, a halogenated salicylanilide anthelmintic, is described in 11 sheep and a goat, humanely killed 4-70 days after accidental overdosage. Status spongiosis of the cerebrum and cerebellum was present, its severity decreasing with time after treatment. Ultrastructurally, vacuoles in the cerebral white matter were seen to be intramyelinic due to splitting of myelin lamellae at the intraperiod lines, indicating myelin oedema. In the optic nerves, Wallerian degeneration and eventual fibrosis and atrophy of the nerves followed myelin vacuolation. Lesions in the optic nerves were particularly advanced in the intracanalicular portion, indicating a compressive neuropathy within the optic canal. Acute retinal lesions consisted of papilloedema, necrosis of the outer retinal layers (especially the photoreceptor layer), and retinal separation in tapetal and non-tapetal areas. In more chronic cases, the outer nuclear layer was diffusely attenuated and generally reduced to a single row of cells.

\section{Article Outline}

Introduction

Materials and Methods 
Animals

Ophthalmoscopic Investigations

Pathology

Results

Ophthalmoscopic Investigations

Gross Lesions

Histological Lesions

Transmission Electron Microscopy

Discussion

Acknowledgements

References

\section{Introduction}

The halogenated salicylanilides are a group of compounds developed mainly for their antiparasitic activity in animals (Swan, 1999). Closantel and rafoxanide, which represent the most important drugs in this group, are used extensively for the control of Haemonchus spp. and Fasciola spp. infestations in sheep and cattle and Oestrus ovis in sheep in many parts of the world, including South Africa (Swan, 1999).

Clinical signs of closantel and rafoxanide toxicity in small stock include inappetence, ataxia, paresis, recumbency, and blindness with mydriasis and papilloedema (Prozesky and Pienaar, 1977; Button et al., 1987; Odiawo et al., 1991; Gill et al., 1999; Swan, 1999; Barlow et al., 2002). There are no reported gross lesions in the central nervous system (CNS), but narrowing of the intracanalicular portion of the optic nerves has been reported in sheep with closantel intoxication (Gill et al., 1999). Histologically, symmetrical status spongiosis of the white matter of the cerebrum, cerebellum and spinal cord, and oedema, demyelination and lytic necrosis of the optic nerves have been described. The pathogenesis of the myelin vacuolation in the nervous system has not been elucidated. Retinopathy has been reported in blind animals (Prozesky and Pienaar, 1977; Button et al., 1987; Seawright, 1989; Borges et al., 1999; Gill et al., 1999; Barlow et al., 2002). There is, however, disagreement on the primary site of retinal damage in salicylanilide 
poisoning in small stock (Gill et al., 1999). Selective involvement of the ganglion cells (Prozesky and Pienaar, 1977; Button et al., 1987; Borges et al., 1999) and degeneration of the outer retinal layers (Gill et al., 1999; Seawright, 1989) have been described. The purpose of the present publication is to describe the progressive development of lesions in the optic nerve and retina and to document the ultrastructural changes in CNS myelin in cases of closantel toxicity in small stock.

\section{Materials and Methods}

\section{Animals}

Eleven sheep used for the study consisted of five lambs aged 2 months from a single farm (nos 6, 9-12) and six lambs aged 3-9 months from different farms (nos 1-5, 8). One Angora goat kid (animal no. 7) aged 6 months was also used. The animals originated from farms where blindness following the administration of closantel (Flukiver; Janssen Animal Health, Sandton, South Africa) had been observed by the owners. Accurate information on the doses administered could not be obtained, but, from inquiries made, it seemed likely that the recommended dose $(10 \mathrm{mg} / \mathrm{kg}$ body weight) had been exceeded in a proportion of animals, sometimes by up to 4 times. Blindness was reported within 2-5 days of treatment. Fixed, dilated pupils and ataxia were noted in sheep 1, 2, 4 and 5, and two animals (nos 3 and 7) showed temporary recumbency.

\section{Ophthalmoscopic Investigations}

Direct and indirect ophthalmoscopy and slit-lamp biomicroscopical examination of five lambs (nos 6,9-12) were performed 1 and 2 weeks after treatment, and subsequently at 2-weekly intervals up to the time of euthanasia. An electroretinogram (ERG) was recorded 2 weeks after overdosing in lambs 9 and 11 and in an age-matched control lamb. The pupils were dilated with tropicamide (Mydriacyl; Alcon Laboratories, Bryanston, South Africa). The ERGs were recorded without general anaesthesia after 25 min of dark adaptation. After topical anaesthesia with proparcaine $\mathrm{HCl}$ (Ophthetic; Allergan, Halfwayhouse, South Africa), a corneal ERG contact lens electrode was positioned. The reference electrode (25-gauge hypodermic needle) was positioned on the midline over the frontalis muscle, and the ground electrode was placed at the tip of the right ear. The retina 
was stimulated with a photo stimulator (model PS22; Grass Instruments, Quincy, MA, USA) placed $20 \mathrm{~cm}$ from the eye. A blue filter was used to obtain a mixed rod and cone response. The ERGs were recorded with an oscilloscope (model 310; Nicolet Instrument Corporation, Madison, WI, USA). The amplification sensitivity was $100 \mu \mathrm{V} / \mathrm{Div}$ and the sweep speed $40 \mathrm{~ms} / \mathrm{DIV}$.

\section{Pathology}

All animals were killed at different intervals after closantel treatment (Table 1), by an intravenous overdose of pentobarbitone sodium, and a complete post-mortem examination was performed. The method of collection, fixation and preparation of tissue specimens for histology has been described (van der Lugt et al., 1996). Briefly, the brain and spinal cord, sciatic nerve, and a range of other tissue specimens were fixed in $10 \%$ neutral buffered formalin. The eyes and the intraorbital portion of the optic nerves were immersed in Zenker's fixative within 10 min of euthanasia. In sheep 1, 2, 6 and 9-12, blocks containing the intracanalicular portion of the optic nerves were decalcified after fixation and trimmed to expose either the transverse or longitudinal surfaces of the optic nerves within the bony canals.

Table 1.

Details of 12 animals with closantel poisoning

\begin{tabular}{|c|c|c|c|}
\hline Arives' na & Writs & 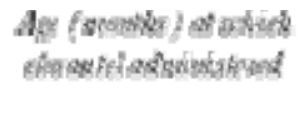 & 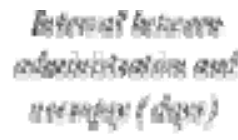 \\
\hline 1 & Ales:B & 3 & 4 \\
\hline 9 & Stowp & 6 & 5 \\
\hline 5 & Shopp & 3 & 19 \\
\hline 4 & Shasp & 8 & is \\
\hline 5 & Sherpe & B & 15 \\
\hline 6) & Shosp & $g$ & भू 1 \\
\hline$z$ & Genst & 5 & 29 \\
\hline \#) & Sharap: & 4 & 36 \\
\hline 8 & Shopp & g & 42 \\
\hline$m$ & Stasep & $q$ & 36 \\
\hline II & Staren: & 9 & 70 \\
\hline 12 & Sherp & 9 & 50 \\
\hline
\end{tabular}

The brains of sheep 1-3, 6 and 9-12 were cut into sections, and blocks were prepared at the level of the olfactory tubercle and cortex, cerebral cortex (frontal, parietal, temporal 
and occipital), basal nuclei, thalamus, mesencephalon, pons and medulla oblongata (two levels). Blocks were also prepared from the spinal cord (cervical, thoracic and lumbosacral portions). From the other animals $(4,5,7,8)$, sections of parietal cerebral cortex, thalamus and spinal cord were cut. Mid-saggital slabs containing the optic nerve were trimmed from each globe. All tissues were processed by routine methods and embedded in paraffin wax, and sections $(5-6 \mu \mathrm{m})$ were cut and stained with haematoxylin and eosin (HE). Selected sections of brain, spinal cord and optic nerves were also stained with luxol fast blue/periodic acid-Schiff/haematoxylin (LFB/PAS/H), luxol fast blue/Holmes (LFB/H) and Masson's trichrome (MT). Ocular sections were also stained with periodic acid-Schiff (PAS). Mounted unstained sections of the eyes of lambs 6 and 9 were examined by fluorescence microscopy.

Specimens of the cerebral subependymal white matter adjacent to the lateral ventricles, collected from sheep 1 and 3, were prepared for transmission electron microscopy (TEM) as previously described (van der Lugt et al., 1996).

\section{Results}

\section{Ophthalmoscopic Investigations}

One week after treatment, the pupils of five sheep $(6,9-12)$ were seen to be dilated, and the menace reflex and direct and consensual pupillary light reflexes were absent in two sheep $(9,11)$. On direct and indirect ophthalmoscopy, both these sheep showed papilloedema but no evidence of retinal degeneration.

One week later, sheep 6 and 9-12 were again examined. All were blind, and the menace reflex and the direct and consensual pupillary light reflexes were absent. On direct and indirect ophthalmoscopy, retinal degeneration characterized by small pale areas in the non-tapetal fundus was seen. At this time there was no papilloedema. Slit-lamp biomicroscopical examination confirmed a focal posterior capsular cataract and remnants of the hyaloid artery in one lamb (no. 11). Two weeks later, retinal degeneration in three sheep (9-11) had worsened and increased tapetal reflectivity was present in sheep 10 . Two weeks later, sheep 11 developed increased tapetal reflectivity and bilateral horizontal nystagmus. 
Sheep 9 and 11 had non-recordable ERGs. The ERG in the control animal consisted of an early negative deflection (a-wave) and a bigger positive deflection (b-wave). In this animal, the ERG amplitudes obtained with the blue filter were $221 \mu \mathrm{V}$ for the a-wave and $620 \mu \mathrm{V}$ for the b-wave, and without a filter $243 \mu \mathrm{V}$ for the a-wave and $701 \mu \mathrm{V}$ for the bwave.

\section{Gross Lesions}

Apart from slight narrowing of the intracanalicular portion of the optic nerves in sheep 8, 10 and 11 , no lesions were noted in tissues or organs at necropsy.

\section{Histological Lesions}

Brain and spinal cord. Lesions in the CNS were all of a similar nature; in eight animals $(1-3,6,9-12)$ examined for symmetry, the lesions were of similar distribution but variable severity. There was bilateral symmetrical status spongiosis of the white matter of the brain and spinal cord. Areas consistently affected by myelin vacuolation included the cerebral white matter adjacent to the lateral ventricles (Fig. 1), optic radiation, thalamic nuclei, brain stem (particularly the pons), and the cerebellar peduncles. The myelin vacuoles were round to ovoid or elongated, generally 5-30 $\mu \mathrm{m}$ in diameter, and empty. Confluence of vacuoles resulted in large loculated areas, sometimes traversed by thin myelin strands, as demonstrated in sections stained with LFB. The vacuolation was particularly extensive in sheep 1-3 and there was a paucity of myelin staining in the most severely affected areas. Myelin vacuolation in the white matter of the spinal cord was mild and inconsistent, and the spinal nerve roots and peripheral nerve were spared. In sheep 9-12, myelin vacuolation was mild and restricted to the periventricular white matter. No evidence of myelin degeneration and no Gitter cells were seen with special stains. The optic chiasma in three animals $(9,10,12)$ showed mild myelin vacuolation, astrocytic gliosis and multifocal Wallerian degeneration. 


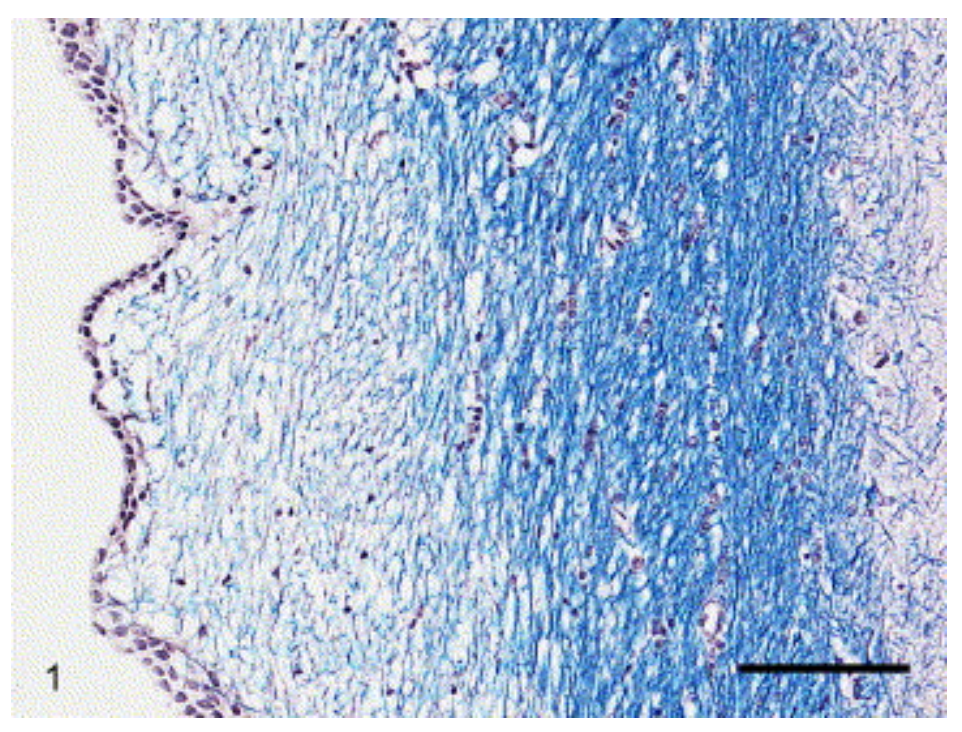

Fig. 1. Cerebrum; sheep 3. Status spongiosis of the periventricular white matter. HE. Bar, $100 \mu \mathrm{m}$.

Optic nerves. Lesions in the optic nerves of sheep 1, 2, 6 and 9-12 were examined. In sheep 1 and 2, killed 4-5 days after treatment, widespread myelin vacuolation in the intracanalicular portions of the nerves was evident (Fig. 2). In the other five sheep, lesions in the intracanalicular portion of the nerves were more chronic than those in the intraorbital and intracranial portions (Fig. 3 and Fig. 4). An irregular line of demarcation separated lesions of different chronicity in the intraorbital portions of the affected nerves (Fig. 4). The changes seen included swelling, fragmentation and loss of myelinated axons, multifocal accumulations of macrophages, gliosis, and thickened pial septa. In more chronic cases, the intracanalicular portion of the nerve was contracted and showed diffuse fibrosis with complete loss of axons and multifocal accumulations of neutrophils and macrophages (Fig. 3). There was severe fibrosis of the meninges. 


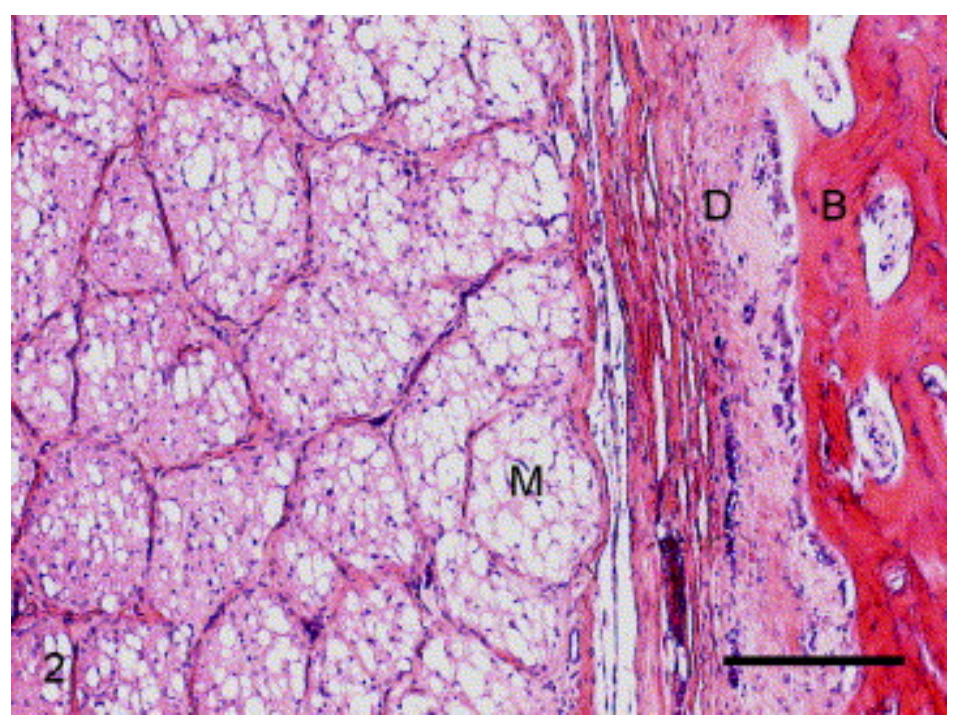

Fig. 2. Optic nerve; sheep 2. Myelin vacuolation (M) in the intracanalicular portion of the optic nerve. D, dura mater; B, bone tissue of optic canal. HE. Bar, $200 \mu \mathrm{m}$.

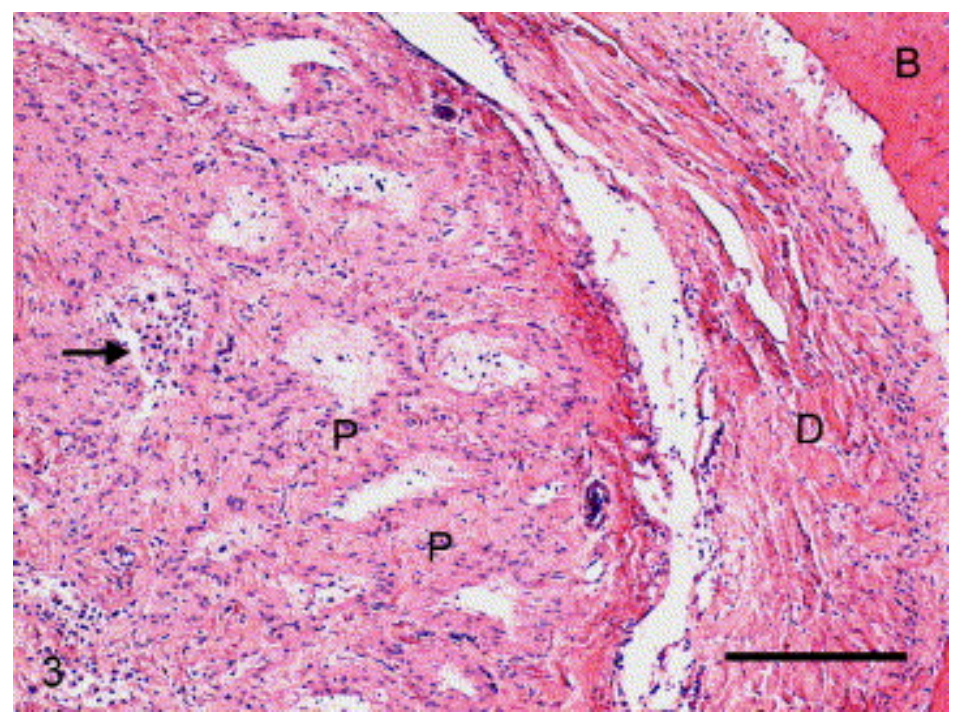

Fig. 3. Optic nerve; sheep 5. Fibrosis of pial septa (P) with associated loss of nerve fibres and multifocal cellular infiltrates (arrow) in the intracanalicular portion of the nerve. Note fibrous thickening of meninges including the dura mater (D) within the bony canal (B). HE. Bar, $200 \mu \mathrm{m}$. 


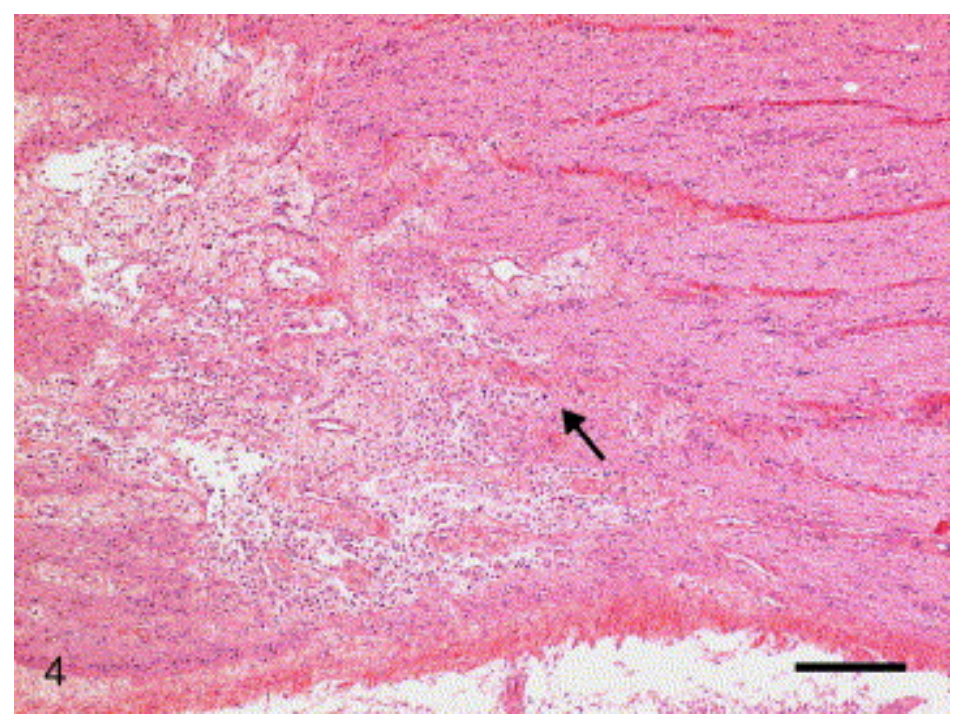

Fig. 4. Optic nerve; sheep 10. There is a clear line of demarcation in this longitudinal section of the intraorbital portion of the optic nerve (arrow). Towards the optic canal (to the left of arrow) lesions consist of necrosis, Wallerian degeneration and loss of myelin fibres, while towards the optic disc (to the right of arrow) the nerve is intact. HE. Bar, $200 \mu \mathrm{m}$.

Retina. In sheep 1 and 2, examined 4-5 days after treatment, the optic disc was markedly swollen due to oedema, while the sensory retina was folded and displaced away from the edges of the disc (Fig. 5). The peripapillary and mid-zonal retina, including both the tapetal and non-tapetal areas, showed multifocal to coalescing necrosis, disappearance of the photoreceptor layer, outer and inner nuclear layers and outer plexiform layer, and focal haemorrhage (Fig. 6). There was occasional haemorrhage and focal neutrophil infiltration in the underlying choroid. In areas of severe necrosis, large sub-retinal spaces contained eosinophilic granular debris and remnants of photoreceptor segments, fibrinous material, free-lying pyknotic nuclei (probably cone and rod nuclei), pigmented epithelial cells, macrophages (sometimes with greyish granular pigment), and red blood cells (Fig. 6). In the remainder of the retina, thinning of the outer nuclear layer, together with stubby remnants of the photoreceptor inner segments or translucent membranous profiles, possibly representing degenerative photoreceptor outer segments, were present (Fig. 7 and Fig. 8). The inner nuclear layer was focally reduced in thickness. A small number of ganglion neurons, usually within or adjacent to foci of necrosis, were swollen and 
chromatolytic and showed dispersion of Nissl substance and nuclear margination or fragmentation (Fig. 8).

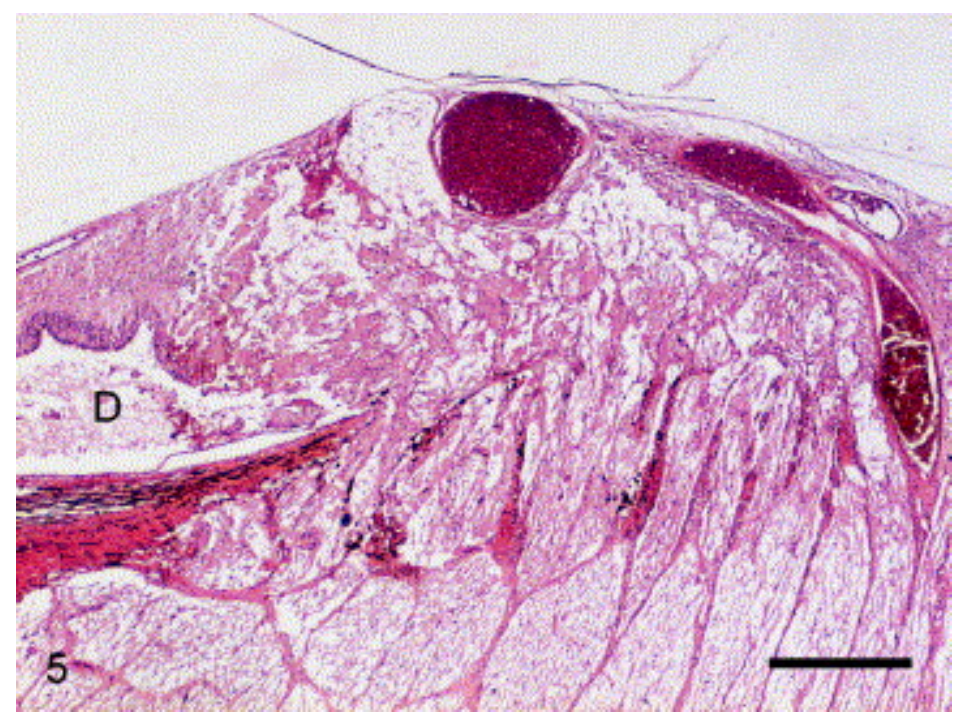

Fig. 5. Eye; sheep 1. Oedema of the optic papilla and nerve, congestion of retinal blood vessels, and lateral displacement of the sensory retina. Note detachment (D) of the retina, forming a large subretinal space. HE. Bar, $50 \mu \mathrm{m}$.

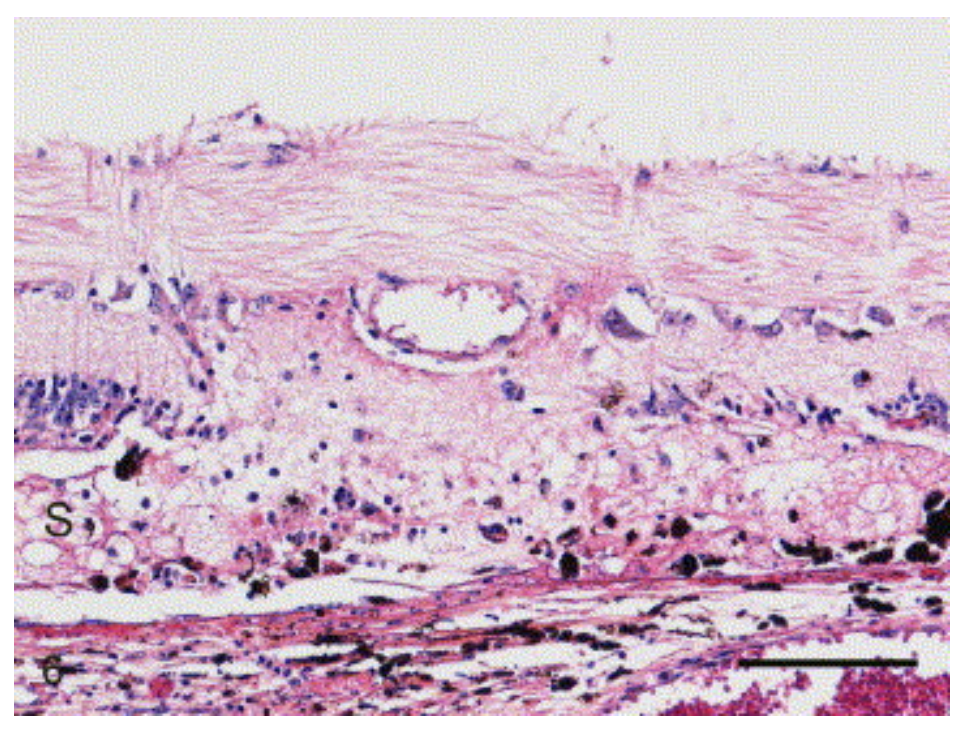

Fig. 6. Eye; sheep 1. Necrosis and loss of outer retinal layers and formation of a subretinal space containing cellular exudate and fibrinous material (S) in the mid-zonal non-tapetal area. HE. Bar, $100 \mu \mathrm{m}$. 


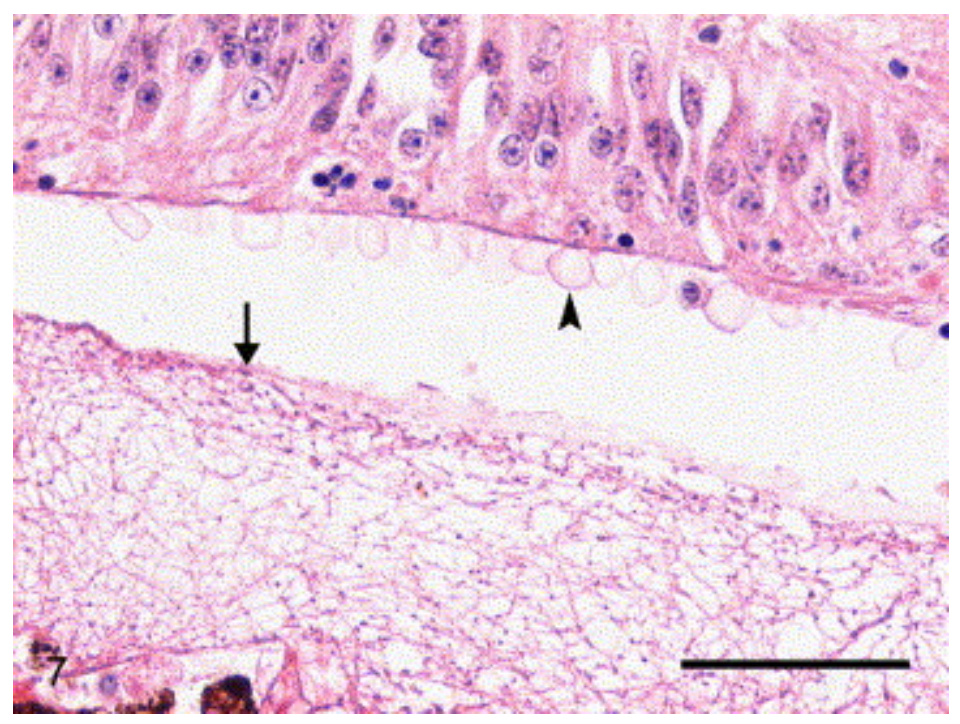

Fig. 7. Eye; sheep 2. Loss of the outer nuclear layer; and sub-retinal space, partly filled with fibrinous material (arrow) in the peripapillary non-tapetal retina. Note irregular membranous profiles representing remnants of photoreceptor outer segments (arrowhead). HE. Bar, $100 \mu \mathrm{m}$.

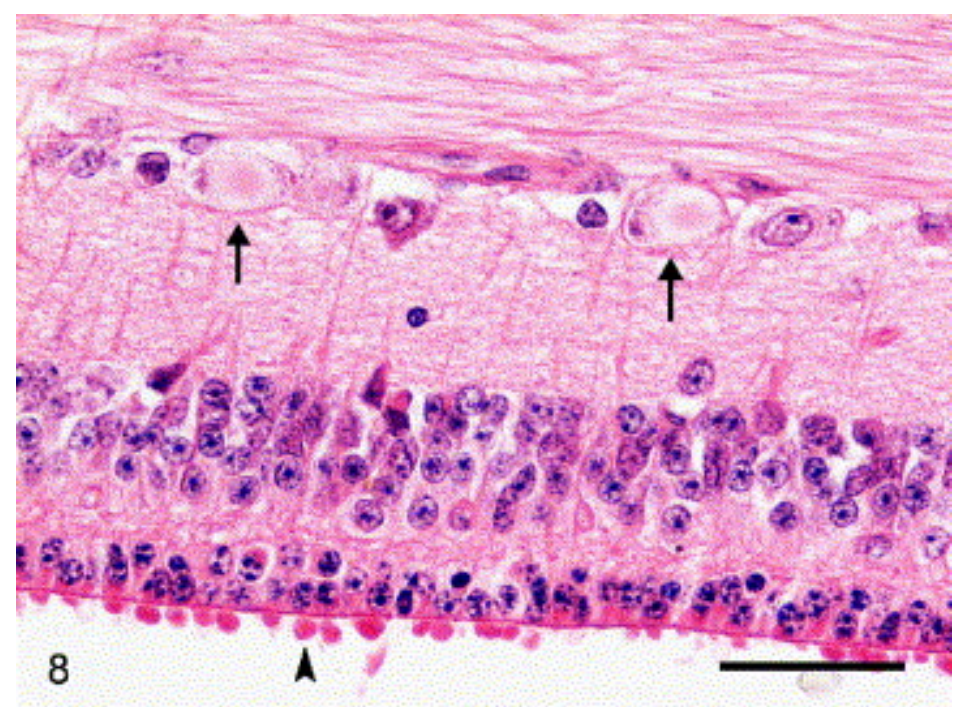

Fig. 8. Eye; sheep 2. Necrosis of ganglion cells (arrows) in the midzonal tapetal retina. The outer nuclear layer is reduced in thickness and the photoreceptor layer is represented by stubby remnants of inner segments (arrowhead). HE. Bar, $100 \mu \mathrm{m}$.

In animals 3-12, killed 10-70 days after treatment, the optic disc was of normal size and the retinal changes were more advanced. A consistent lesion was diffuse attenuation of the outer nuclear layer, which was generally reduced to a single row of cells, with focal 
loss of the outer nuclear layer and scattered areas of nuclear pyknosis (Fig. 9). The photoreceptor layer was absent in most areas. The inner retinal layers and occasionally the ganglion cell layer contained small groups of heavily pigmented cells and extracellular, oval and elongated, melanin granules. There was variable reduction in the numbers of ganglion cells (Fig. 9). In three animals $(7,11,12)$ additional chronic lesions were characterized by marked atrophy of the retina, loss of all layers, extensive pigment cell migration, and glial scars (Fig. 10). There was no autofluorescent or PAS-positive pigment in the retinal pigmented epithelium.

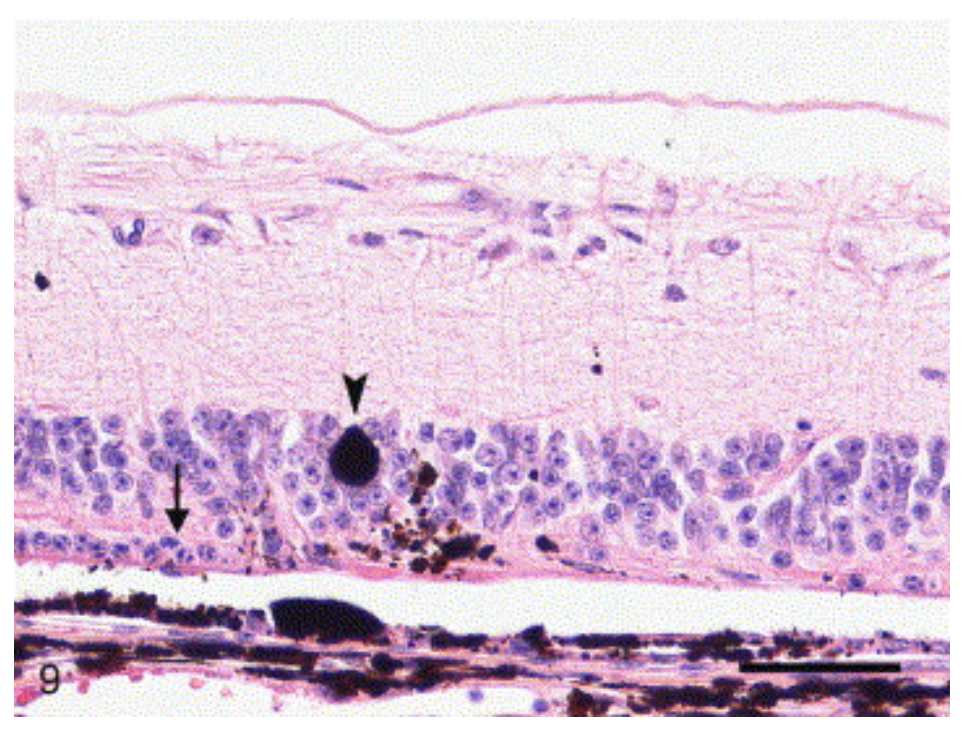

Fig. 9. Eye; sheep 6. More advanced retinal lesions in the midzonal tapetal retina. Lesions are characterized by: disappearance of the photoreceptor layer; hyperplasia and hypertrophy of pigmented epithelium, with pigment cell migration (arrowhead); a single row of cells in the outer nuclear layer (arrow) or discontinuation of the outer nuclear layer; and reduction in the number of ganglion cells. HE. Bar, $50 \mu \mathrm{m}$. 


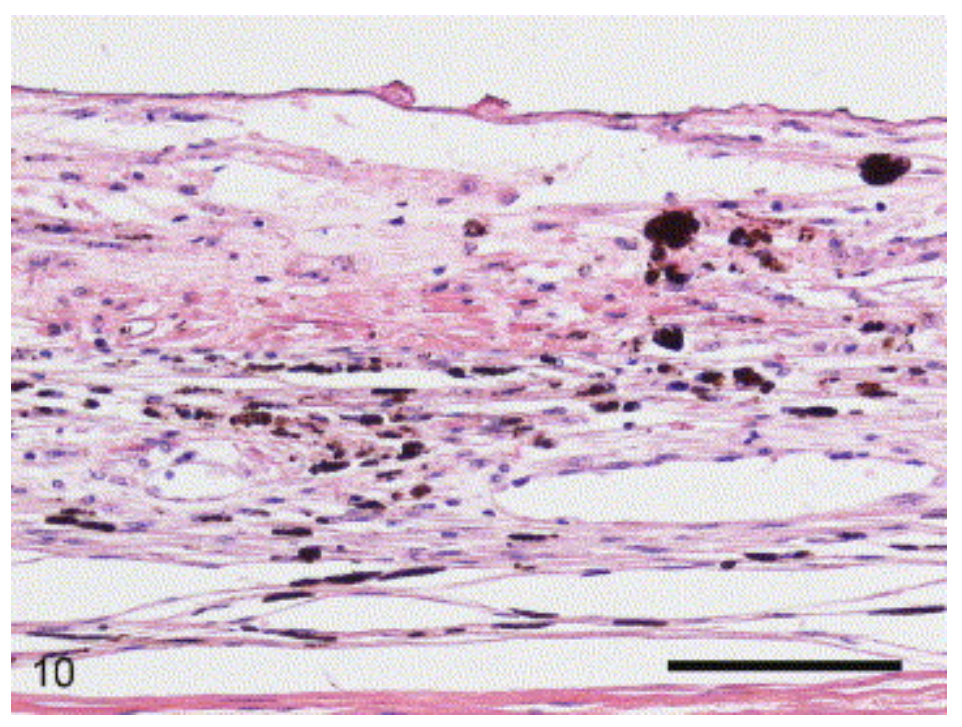

Fig. 10. Eye; animal 10 (goat). Chronic retinal lesions consist of loss of normal architecture with atrophy, pigment cell migration, and scar tissue formation. HE. Bar, $100 \mu \mathrm{m}$.

Other organs and tissues. No significant lesions were evident.

Transmission Electron Microscopy

The vacuoles in the cerebral white matter corresponded to distension of myelin sheaths (Fig. 11) due to splitting of myelin lamellae at the intraperiod lines (Fig. 11, inset).

Vacuoles of variable size were especially noticeable at the outer portions of the myelin sheath of larger axons. Most vacuoles were empty, but a few contained small membranous fragments. There was marked distension of extracellular and perivascular spaces. Axons were well preserved in the affected nerve fibres. Glial cells, endothelial cells and neurons showed no abnormalities, and myelin breakdown was not confirmed. 


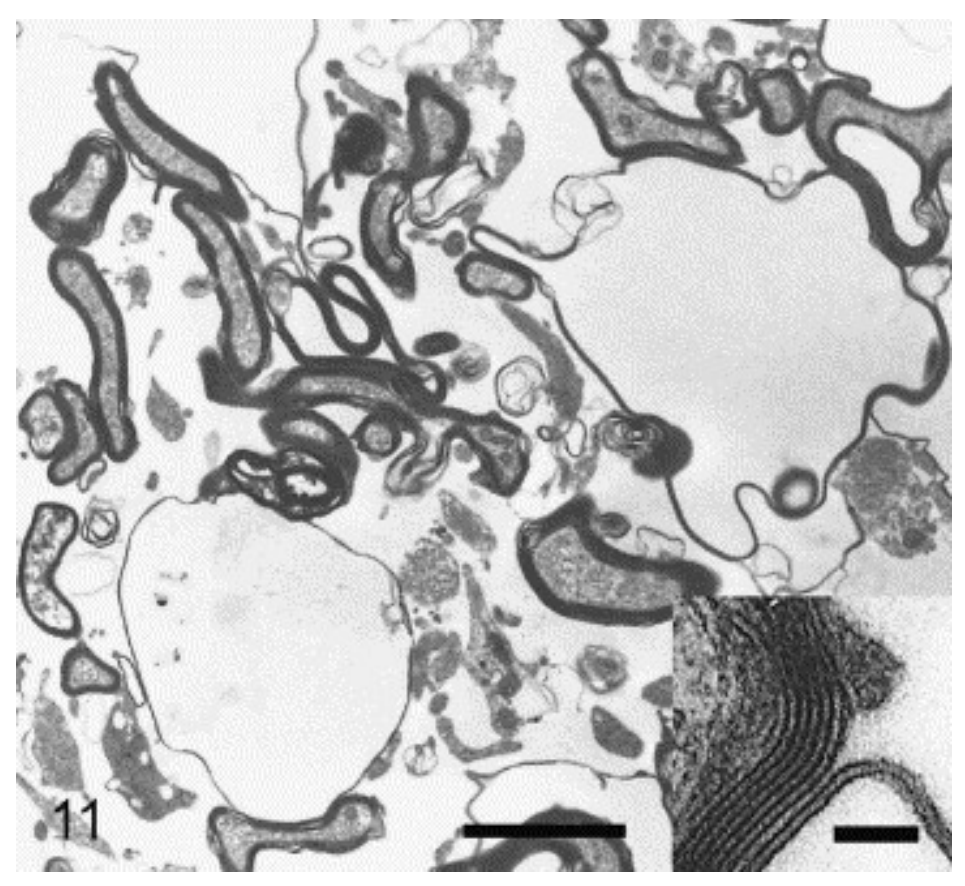

Fig. 11. Cerebrum; sheep 3. Multiple intramyelinic vacuolar spaces and distended extracellular spaces. TEM. Bar, $5 \mu \mathrm{m}$. Inset: Higher magnification to illustrate splitting of myelin lamellae at the intraperiod line. Bar, $0.1 \mu \mathrm{m}$.

\section{Discussion}

In this study of accidental salicylanilide poisoning, status spongiosis of the cerebral and cerebellar white matter was a consistent lesion. This finding accords with previous publications (Prozesky and Pienaar, 1977; Obwolo et al., 1989; Borges et al., 1999).

Only mild spongy changes were seen in the spinal cord and the peripheral myelin was not affected. The intensity of the myelin vacuolation decreased progressively after treatment and would probably have resolved without leaving residual lesions in the nervous system. Intramyelinic vacuolation due to separation of lamellae along the intraperiod line appeared to be the structural basis for the status spongiosis observed.

The term status spongiosis denotes spongy vacuolation of white matter as seen by light microscopy (Adornato and Lampert, 1971). Electron microscopy is often required to demonstrate the morphological basis for the vacuolation (Summers et al., 1995), which may be associated with intracellular, extracellular and intramyelinic accumulation of fluid or may represent an artefact (Adornato and Lampert, 1971). Such vacuolation is 
commonly intramyelinic, the accumulation of fluid resulting in splitting of the intraperiod line (Kreutzberg et al., 1997).

Several so-called spongiform myelinopathies are characterized by myelin splitting at the intraperiod line and the subsequent formation of intramyelinic vacuoles. Myelin splitting may be caused by the toxic effects of substances of exogenous origin, as in experimental poisoning by hexachlorophene (Lampert et al., 1973; Towfighi, 1980), triethyl tin (Jacobs et al., 1977; Watanae, 1980), cuprizone (Suzuki and Kikkana, 1969), isonicotinic acid hydrazide (Lampert and Schochet, 1986), nitrobenzene (Morgan et al., 1985) and aniline (Okazaki et al., 2001), or by substances of endogenous origin, as in disorders of intermediary metabolism. In domestic animals, intoxications characterized by separation of myelin lamellae at the intraperiod line include those caused by overdosage with ammonia (Cho and Leipold, 1977) or copper (Morgan, 1973), ingestion of plants such as Stypandra imbricata (Huxtable et al., (1992) and Huxtable et al., 1980; Main et al., 1981) and Helichrysum argyrosphaerum (van der Lugt et al., 1996) or the fungus Stenocarpella maydis (= Diplodia maydis) (Kellerman et al., 1991 and Kellerman et al., 1985; Prozesky et al., 1994). Maple syrup urine disease, a metabolic disorder causing intramyelinic vacuole formation in the brain, has been described in calves (Harper et al., 1989 and Harper et al., 1986).

The pathogenesis of myelin splitting at the intraperiod line is not known. The encephalopathy in bovine maple syrup urine disease appears to be associated with a diminution of gamma-aminobutyric acid (GABA)-mediated neurotransmission (Dodd et al., 1992). In toxicity with nitrobenzene and aniline, uncoupling of mitochondrial oxidative phosphorylation in oligodendrocytes was suggested as the cause of the myelinic vacuolation (Morgan et al., 1985; Okazaki et al., 2001). Inhibition of oxidative phosphorylation interferes with adenosine triphosphate (ATP) production and causes disturbances in transmembrane energy-bound electrolyte transport (Verity, 1997). In studies with aniline neurotoxicity in rats, a small amount of membranous debris was found in the cytoplasm of oligodendrocytes, possibly indicating impairment of these cells (Okazaki et al., 2001). The anthelmintic spectrum of closantel has been linked to the compound's ability to uncouple oxidative phosphorylation, but it is not known whether this mechanism could account for the toxic effects in sheep and goats (Bacon et al., 1998; 
Swan, 1999). A primary myelinotoxic effect of salicylanilides on the myelin sheath, especially since the vacuolation resulting from overdosage is widely distributed throughout the nervous system, cannot be excluded (Kreutzberg et al., 1997). Pathological changes in the optic nerves were confirmed in all cases examined. The nature and progression of the lesions showed initial myelin vacuolation leading to Wallerian degeneration and eventual irreversible fibrosis and contraction of the nerve. Optic nerve lesions in all animals, except for the two acute cases (1 and 2), were generally more chronic in the intracanalicular portion of the nerve than in the intraorbital and intracranial portions. Similar optic nerve lesions were reported previously in closantel poisoning (Borges et al., 1999; Gill et al., 1999), Helichrysum argyrosphaerum poisoning (van der Lugt et al., 1996), and Stypandra imbricata (Main et al., 1981) and Stypandra glauca intoxication (Whittington et al., 1988). A common pathogenesis for the optic neuropathy, namely initial myelin oedema followed by swelling and compression of the nerve within the bony canal, has been proposed in these intoxications. The first ophthalmological signs were absence of pupillary light reflexes and papilloedema. Loss of light reflexes indicates optic nerve or retinal damage, or both (Scagliotti, 1999). Depigmentation of the non-tapetum and increased reflectivity of the tapetum indicate retinal degeneration. The "a" wave of the ERG is generated by the photoreceptors and the "b" wave by Müller's cells and bipolar neurons (Sims, 1999). A normal ERG may be obtained despite ganglion cell degeneration. An ERG was performed only after retinal changes were ophthalmoscopically visible, making it impossible to speculate on the presence of retinal damage during the first week after treatment. Two weeks after treatment, non-recordable ERGs were obtained; this was consistent with the retinal degeneration seen ophthalmoscopically (Sims, 1999). The posterior capsular cataract and remnants of the hyaloid artery in sheep 11 were regarded as coincidental findings.

It would seem that closantel has a direct retinotoxic effect in small stock. The photoreceptor outer segments are composed largely of compacted plasma membranes, somewhat analogous to myelin, and it was suggested that a common toxic mechanism underlies the injury to the outer retina and myelin (Gill et al., 1999). Retinal lesions in our cases were characterized by necrosis, loss of the photoreceptor layer and outer 
nuclear layer, and retinal separation. In more chronic lesions the outer nuclear layer was generally reduced to a single row of neuronal nuclei, with multifocal loss of the outer nuclear layer and photoreceptor layer. The change in the outer nuclear layer may be interpreted as selective survival of cone nuclei, especially because tiny blunt processes, probably representing persistent cones, were evident in the photoreceptor layer. It would therefore seem that the photoreceptor layer (possibly the rods) is primarily affected in acute halogenated salicylanilide poisoning. There was preservation of the inner retinal layers until later in the course of the intoxication, at which point a reduction in ganglion cells was noted. The observed lesions in the outer retina were not secondary to optic neuropathy, as retrograde degeneration of the photoreceptor layer is not seen in optic nerve damage, even when the nerve is completely transected (Spencer, 1986). Electron microscopical studies may clarify the pathogenesis of the retinopathy. A similar type of retinopathy was described previously in closantel toxicosis (Seawright, 1989; Gill et al., 1999; Barlow et al., 2002). Acute lesions (papilloedema, retinal haemorrhage and exudation within the subretinal space) as seen in sheep 1 and 2 have not been reported previously but may have been related to dose and to the short interval between closantel administration and necropsy.

The photoreceptor outer segments also seem to be primary targets in other toxic retinopathies in domestic animals, such as poisoning by S. glauca (Whittington et al., 1988), S. imbricata (Main et al., 1981) and bracken fern (Pteridium aquilinum) (Watson et al., 1972a and Watson et al., 1972b). Closantel intoxication may also cause blindness in dogs. Thus, a dog that received six times the recommended dose showed papilloedema, retinal haemorrhages, and optic neuritis (McEntee et al., 1995).

Retinal ganglion cells were affected in two ways, depending on the stage of the intoxication. In acutely affected animals (nos 1,2), chromatolysis of cell bodies was noted. Prozesky and Pienaar (1977) reported similar changes in ganglion cells in rafoxanide toxicity in sheep. The association of ganglion cell degeneration with diffuse myelin swelling in the optic nerves suggested that the ganglion cell lesions either reflected a direct toxic effect on the neurons or followed axonal injury within the optic nerve. In more chronic cases, a reduction in the number of ganglion cells was probably 
attributable to degeneration and loss of axons in the optic nerves.

\section{References}

Adornato and Lampert, 1971 B. Adornato and P. Lampert, Status spongiosis of nervous tissue, Acta Neuropathologica (Berl.) 19 (1971), pp. 271-289.

Bacon et al., 1998 J.A. Bacon, R.G. Ulrich, J.P. Davis, E.M. Thomas, S.S. Johnson, G.A.

Condor, N.C. Sangster, J.T. Rothwell, R.O. McCracken, B.H. Lee, M.F. Clothier, T.G.

Geary and D.P. Thompson, Comparative in vitro effects of closantel and selected $\beta$ ketoamide anthelmintics on a gastrointestinal nematode and vertebrate liver cells, Journal of Veterinary Pharmacology and Therapeutics 21 (1998), pp. 190-196.

Barlow et al., 2002 A.M. Barlow, J.A.E. Sharpe and E.A. Kincaid, Blindness in lambs due to inadvertent closantel overdose, Veterinary Record 151 (2002), pp. 25-26.

Borges et al., 1999 A.S. Borges, L.C.N. Mendes, A.L. De Andrade, G.F. Machado and J.R. Peiro, Optic neuropathy in sheep associated with overdosage of closantel, Veterinary and Human Toxicology 41 (1999), pp. 378-380.

Button et al., 1987 C. Button, I. Jerrett, P. Alexander and W. Mizon, Blindness in kids associated with overdose of closantel, Australian Veterinary Journal 64 (1987), p. 226. Cho and Leipold, 1977 D.Y. Cho and H.W. Leipold, Experimental spongy degeneration in calves, Acta Neuropathologica (Berl.) 39 (1977), pp. 115-127.

Dodd et al., 1992 P.R. Dodd, S.H. Williams, A.L. Gundlach, P.A.W. Harper, P.J. Healy, J.A. Dennis and A.R. Johnston, Glutamate and $\gamma$-aminobutyric acid neurotransmitter systems in the acute phase of maple syrup urine disease and citrullinemia encephalopathies in newborn calves, Journal of Neurochemistry 59 (1992), pp. 582-590. Gill et al., 1999 P.A. Gill, R.W. Cook, J.G. Boulton, W.R. Kelly, B. Vanselow and L.A. Reddacliff, Optic neuropathy and retinopathy in closantel toxicosis of sheep and goats, Australian Veterinary Journal 77 (1999), pp. 259-261.

Harper et al., 1989 P.A.W. Harper, J.A. Dennis, P.J. Healy and G.K. Brown, Maple syrup urine disease in calves: a clinical, pathological and biochemical study, Australian Veterinary Journal 66 (1989), pp. 46-49.

Harper et al., 1986 P.A.W. Harper, P.J. Healy and J.A. Dennis, Ultrastructural findings in maple syrup urine disease in poll Hereford calves, Acta Neuropathologica (Berl.) 71 (1986), pp. 316-320. 
Huxtable et al., (1992) Huxtable, C.R., Dorling, P.R. and Colegate, S.M. (1992). Stypandra poisoning: the role of stypandrol and proposed pathomechanisms. In: Poisonous Plants: Proceedings of the Third International Symposium, L.F. James, R.F. Keeler, E.M. Bailey, P.R. Cheeke and M.P. Hegarty, Eds, Iowa State University Press, Ames, pp. 464-468.

Huxtable et al., 1980 C.R. Huxtable, P.R. Dorling and D.H. Slatter, Myelin oedema, optic neuropathy and retinopathy in experimental Stypandra toxicosis, Neuropathology and Applied Neurobiology 6 (1980), pp. 221-232.

Jacobs et al., 1977 J.M. Jacobs, J.E. Crertier and J.B. Cavanagh, Acute effects of triethyl tin on the rat myelin sheath, Neuropathology and Applied Neurobiology 3 (1977), pp. 169-181.

Kellerman et al., 1991 T.S. Kellerman, L. Prozesky, R.A. Schultz, C.J. Rabie, H. Van Ark, B.P. Maartens and A. Lübben, Perinatal mortality in lambs of ewes exposed to cultures of Diplodia maydis (= Stenocarpella maydis) during gestation, Onderstepoort Journal of Veterinary Research 58 (1991), pp. 297-308.

Kellerman et al., 1985 T.S. Kellerman, C.J. Rabie, G.C.A. Van der Westhuizen, N.P.J. Kriek and L. Prozesky, Induction of diplodiosis, a neuromycotoxicosis, in domestic ruminants with cultures of indigenous and exotic isolates of Diplodia maydis, Onderstepoort Journal of Veterinary Research 52 (1985), pp. 35-42.

Kreutzberg et al., (1997) Kreutzberg, G.W., Blakemore, W.F. and Graeber, M.B. (1997). Cellular pathology of the central nervous system. In: Greenfield's Neuropathology, 2nd Edit., D.I. Graham and P.L. Lantos, Eds, Arnold, London, pp. 85-140. Lampert et al., 1973 P. Lampert, J. O’Brien and R. Garrett, Hexachlorophene encephalopathy, Acta Neuropathologica (Berl.) 23 (1973), pp. 326-333.

Lampert and Schochet, 1986 P.W. Lampert and S.S. Schochet, Electron microscopic observations on experimental spongy degeneration of the cerebellar white matter, Journal of Neuropathology and Experimental Neurology 27 (1986), pp. 210-220.

Main et al., 1981 D.C. Main, D.H. Slatter, C.R. Huxtable, I.C. Constable and P.R. Dorling, Stypandra imbricata ("blindgrass") toxicosis in goats and sheep-clinical and pathological findings in 4 field cases, Australian Veterinary Journal 57 (1981), pp. 132135.

McEntee et al., 1995 K. McEntee, M. Grauwels, C. Clercx and M. Henroteaux, Closantel intoxication in a dog, Veterinary and Human Toxicology 37 (1995), pp. 234-236. 
Morgan, 1973 K.T. Morgan, Chronic copper toxicity of sheep: an ultrastructural study of spongiform leucoencephalopathy, Research in Veterinary Science 15 (1973), pp. 88-95. Morgan et al., 1985 K.T. Morgan, E.A. Gross, O. Lyght and J.A. Bond, Morphologic and biochemical studies of a nitrobenzene-induced encephalopathy in rats, Neurotoxicology 6 (1985), pp. 105-116.

Obwolo et al., 1989 M.J. Obwolo, G.O. Odiawo and J.S. Ogaa, Toxicity of a closantelalbendazole mixture in a flock of sheep and goats, Australian Veterinary Journal 66 (1989), pp. 229-230.

Odiawo et al., 1991 G.O. Odiawo, J.S. Ogaa, J. Ndikuwera and J.E. Moulton, Acute amaurosis in sheep due to rafoxanide neurotoxicity, Zimbabwe Veterinary Journal 22 (1991), pp. 64-69.

Okazaki et al., 2001 Y. Okazaki, K. Yamashita, M. Sudo, M. Tsuchitani, I. Narama, R. Yamaguchi and S. Tateyama, Neurotoxicity induced by a single oral dose of aniline in rats, Journal of Veterinary Medical Science 63 (2001), pp. 539-546.

Prozesky et al., 1994 L. Prozesky, T.S. Kellerman, D.P. Swart, B.P. Maartens and R.A. Schultz, Perinatal mortality in lambs exposed to cultures of Diplodia maydis (= Stenocarpella maydis) during gestation. A study of the central nervous system lesions, Onderstepoort Journal of Veterinary Research 61 (1994), pp. 247-253.

Prozesky and Pienaar, 1977 L. Prozesky and J.G. Pienaar, Amaurosis in sheep resulting from treatment with rafoxanide, Onderstepoort Journal of Veterinary Research 44 (1977), pp. 257-260.

Scagliotti, (1999) Scagliotti, R.H. (1999). Comparative neuro-ophthalmology. In:

Veterinary Ophthalmology, 3rd Edit., K.N. Gelatt, Ed., Lippincott Williams \& Wilkins, Philadelphia, pp. 1307-1400.

Seawright, (1989) Seawright, A.A. (1989). Animal Health in Australia, Vol. 2, Chemical and Plant Poisonings, 2nd Edit., Australian Government Publishing Service, Canberra, pp. 331-332.

Sims, (1999) Sims, M.H. (1999). Electrodiagnostic evaluation of vision. In: Veterinary Ophthalmology, 3rd Edit., K.N. Gelatt, Ed., Lippincott Williams \& Wilkins, Philadelphia, pp. 483-507.

Spencer, (1986) Spencer, W.H. (1986). Optic nerve. In: Ophthalmic Pathology: an Atlas and Textbook, 3rd Edit., W.H. Spencer, Ed., W.B. Saunders, Philadelphia, pp. 23372458. 
Summers et al., (1995) Summers, B.A., Cummings, J.F. and De Lahunta, A. (1995). Veterinary Neuropathology, Mosby, St Louis, pp. 1-67, 214-236.

Suzuki and Kikkana, 1969 K. Suzuki and Y. Kikkana, Status spongiosis of CNS and hepatic damage induced by cuprizone (biscyclohexanone oxalyldihydrazone), American Journal of Pathology 54 (1969), pp. 307-325.

Swan, 1999 G.E. Swan, The pharmacology of halogenated salicylanilides and their anthelmintic use in animals, Journal of the South African Veterinary Association 70 (1999), pp. 61-70.

Towfighi, (1980) Towfighi, J. (1980). Hexachlorophene. In: Experimental and Clinical Neurotoxicology, P.S. Spencer and H.H. Schaumburg, Eds, Williams \& Wilkins, Baltimore and London, pp. 440-455.

van der Lugt et al., 1996 J.J. van der Lugt, J. Olivier and P. Jordaan, Status spongiosis, optic neuropathy, and retinal degeneration in Helichrysum argyrosphaerum poisoning in sheep and a goat, Veterinary Pathology 33 (1996), pp. 495-502.

Verity, (1997) Verity, M.A. (1997). Toxic disorders. In: Greenfield's Neuropathology, 6th Edit., D.I. Graham and P.L. Lantos, Eds, Arnold, London, pp. 755-811. Watanae, (1980) Watanae, I. (1980). Organotins (triethyltin). In: Experimental and Clinical Neurotoxicology, P.S. Spencer and H.H. Schaumburg, Eds, Williams \& Wilkins, Baltimore and London, pp. 545-557.

Watson et al., 1972a W.A. Watson, K.C. Barnett and S. Terlicki, Progressive retinal degeneration (bright blindness) in sheep: a review, Veterinary Record 91 (1972), pp. 665-670.

Watson et al., 1972b W.A. Watson, S. Terlicki, D.S.P. Patterson, C.N. Herbert and J.T. Done, Experimentally produced progressive retinal degeneration (bright blindness) in sheep, British Veterinary Journal 128 (1972), pp. 457-469.

Whittington et al., 1988 R.J. Whittington, J.E. Searson, S.J. Whittaker and J.R.W. Glastonbury, Blindness in goats following ingestion of Stypandra glauca, Australian Veterinary Journal 65 (1988), pp. 176-181. 